incrementará su importancia como institución para una defensa de Europa más autónoma.

\title{
V. CONSIDERACIONES FINALES
}

A lo largo de las diversas Ponencias de este trabajo, el análisis de su conjunto permite formular unas consideraciones finales sobre los planteamientos y posibles realidades de la Unión Europea Occidental. De forma positiva los términos claros de la situación actual podrían expresarse en el hecho reiteradamente formulado por todos los participantes de la UEO no sólo en lo sucedido hasta ahora, șino con vistas al futuro próximo, de que es solamente una organización política, para la poșible adopción de decisiones conjuntas de los europeos; pero no únicamente de carácter positivo sino también de seguridad; sin que ello suponga la creación de una organización militar, porque la estructura de defensa militar de la seguridad habrá de mantenerse dentro del dispositivo militar de la OTAN, los convenios de participación de Francia y los que se acuerderi con España.

Al mismo tiempo y por lo que se refiere a España, a mediados de noviembre de 1988 se ha formulado de modo concreto la invitación para formar parte de la citada Organización, firmándose el correspondiente protocolo de adhesión. Y en este aspecto, aunque todas las personalịdades responsables han expreșado su dișposición favorable, algunas declaraciones, al condicionar la aceptación de nuestra incorporación a la UEO expresan en su interpretación una serie de conceptos que podrían suponer algunas contradicciones que afectan no sólo a la situación española, sino también a las relaciores entre los distintos países de la Organización. Pero la incorporación de España al foro de la UEEO debe verse como la definitiva decisión de apoyar la defensa occidental, reforzando el llamado "pilar europeo", en momentos de unificación continental.

Como concepto político, la formulación relativa a la seguridad de la UEO sirve para expresar de algunna forma el interés de todos los europeos, para poder ejercer mayor influencia en el momento de adoptar y tomar decișiones, que hasta ahora en gran manera estaban subordinadas al criterio de Estados Unịdos.

Estas apreciaciones podrían servir para tratar de entender los diferentes criterios y contrastes que se perciben entre los participantes de la UEO tanto en sus relaciones bilaterales como colectivas; existen también aspectos que se reiteran de forma más concreta cuando se trata de analizar y sopesar la relatividad de la contribución española a la efectividad de la UEO. 
Si de un .lado se ha reiterado el antiguo concepto atlántiço del "pilar europeo", también ha surgido ahora la referencia a la "plataforma" como mención de lo tratado en La Haya, al aludir a los propósitos de reactivación de la vieja UEO.

En estos momentos lós europeos son conscientes "y así lo han manifestado, de la exigencia de este foro de la UEO, para expresión de las decisiones conjuntas, no sólo políticas sino también de seguridad; pero ello racusa también el efecto de que, pese a las formulaciones sobre el. propósito. de continuidad y firmeza de Alianza y. la decisión, de continuăr en la estrategia de disuasión levanten recelo en EE. UU. y en suma el "pilar. americano" se muestre también receloso sobre la sinceridad de la postura europea, porque pese a los reiterados propósitos de fortalecimiento del despligue, no se aprecia un simultáneo respaldo de su mayor contribución económica a la defensa militar.

En el juego de las contradicciones de los planteamientos de seguridad y en la pugna de las propuestas de desarme; parece que tanto en la posición de los europeos como también en la de EE. UU. ninguna de las partes creyera sinceramente en la efectividad de los argumentos que aluden, porque de forma más o menos consciente entienden que tal desencadenamiento de la acción adversaria no se va a producir, al menos inicialmente, en el llamado "pilar europeo".

El hecho de que actualmente existe en las: Grandes Potencias una conciencia de interés de negociación y reducción de la amenaza, permite crear aquella sensación tranquilizadora, pero sin que ello evite la continuidad de amenazas periféricas de mayor o menor alcance, en espacios más o menos próximos al ámbito de responsabilidad de la Alianza, y por ello el mantenimiento de la "credibilidad del empeño" por los antagonistas, fuerza a la existencia y mantenimiento de los despliegues de seguridad. Precisamente esta referencia a la voluntad de armonizar una acción conjunta de los europeos se refleja con motivo del envio de unidades navales para la seguridad de navegación de los petroleros en el Golfo Pérsico.

En el concepto global de la seguridad y en esta observación de espacios alejados, conviene tener presente que últimamente en algunas zonas del Extremo Oriente y del Pacífico, el examen de la situación ha llevado al Japón al aumento de sus gastos de defensa militar e incluso a la asignación de parte de sus inversiones -el seis por ciento de sus presupuestos de defensano sólo al mejoramiento de los medios propios que hasta ahora se titulaban "fuerzas de autodefensa", sino al apoyo y asistencia en los procesos de seguridad de algunos países de la región, para evitar -según se argumenta-

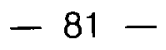


el incremento de la influencia soviética en aquèl espacio. Y todo ello podría trascender también hacia alguna mayor orientación norteamericana en el ámbito del Pacífico Occidental, y que en determinadas circunstancias posiblemente alcanzar una mayor prioridad respecto a los planteamientos que hasta ahora prevalecian hacia el espacio atlántico.

$Y$ se señalan estas circunstancias en zonas alejadas de los problemas y responsabilidad directa de la Alianza Atlántica, porque ello puede pesar en los condicionamientos de nuestra participación en la UEO cuando se han . formulado en cierto modo, el interrogante sobre la forma en que por parte española se podría aportar un concurso de fuerzas, no a la estructura permanente de mandos integrados, sino a la posible participación en hechos y situaciones en que la actuación correspónda directamente a la responsabilidad del mando supremo en Europa (SACEUR). En este caso tal vez se apunta el interés actual de la UEO y también por nuestra parte a algún concurso de participación en la Fuerza Móvil de la Alianza (AMF), donde podria tener capacidad de acción con el aporte de Fuerzas Móviles de Intervención Rápida.

Estas circunstancias tendrán también un reflejo directo en la planificación de las misiones y acciones que corresponden a. las decisiones de operatividad ante las crisis y amenazas que puedan producirse a los países de la Alianza fuera del esquema del despliegue centro-europeo, y que en el caso español cabrian plenamente en el espacio del Mediterráneo Occidental.

EL PRESIDENTE DEL SEMINARIO 